\title{
Hot-embossing of microstructures on addition-curing polydimethylsiloxane films
}

\author{
Vudayagiri, Sindhu; Yu, Liyun; Hassouneh, Suzan Sager; Skov, Anne Ladegaard
}

Published in:

Proceedings of SPIE

Link to article, DOI:

$10.1117 / 12.2009469$

Publication date:

2013

Link back to DTU Orbit

Citation (APA):

Vudayagiri, S., Yu, L., Hassouneh, S. S., \& Skov, A. L. (2013). Hot-embossing of microstructures on additioncuring polydimethylsiloxane films. In Proceedings of SPIE: The International Society for Optical Engineering SPIE - International Society for Optical Engineering. Progress in Biomedical Optics and Imaging - Proceedings of SPIE https://doi.org/10.1117/12.2009469

\section{General rights}

Copyright and moral rights for the publications made accessible in the public portal are retained by the authors and/or other copyright owners and it is a condition of accessing publications that users recognise and abide by the legal requirements associated with these rights.

- Users may download and print one copy of any publication from the public portal for the purpose of private study or research.

- You may not further distribute the material or use it for any profit-making activity or commercial gain

- You may freely distribute the URL identifying the publication in the public portal 


\title{
Hot-embossing of microstructures on addition-curing polydimethylsiloxane films
}

\author{
Sindhu Vudayagiri, Liyun Yu, Suzan Sager Hassouneh, Anne Ladegaard Skov* \\ The Danish Polymer Centre, Department of Chemical and Biochemical Engineering, DTU, 2800 Kgs. Lyngby, \\ Denmark
}

\begin{abstract}
To our knowledge no known technologies or processes are commercially available for embossing microstructures and sub-micron structures on elastomers like silicones in large scale production of films. The predominantly used technologies to make micro-scale components for micro-fluidic devices and microstructures on PDMS elastomer are 1) reaction injection molding 2) UV lithography and 3) photolithography, which all are time-consuming and not suitable for large scale productions. A hot-embossing process to impart micro-scale corrugations on an addition curing vinyl terminated PDMS (polydimethyl siloxane) film, which is thermosetting elastomer, was established based on the existing and widely applied technology for thermoplasts. We focus on hot-embossing as it is one of the simplest, most costeffective and time saving methods for replicating structures for thermoplasts. Addition curing silicones are shown to possess the ability to capture and retain an imprint made on it 10-15 minutes after the gel-point at room temperature. This property is exploited in the hot-embossing technology.
\end{abstract}

Keywords: Embossing, PDMS, carrier web, corrugations, elastomer, DEAP.

\section{INTRODUCTION}

In the large scale manufacture of dielectric electroactive polymers (DEAPs) by Danfoss Polypower A/S, the surface of the PDMS elastomer films are imparted with micro-scale corrugation lines (Figure 1) which enhance the performance of the films as actuators and generators due to the directional anisotropy (Figure 2) caused by the thick corrugation lines and it furthermore allows for high strains of the metallic electrodes.[1,2] The films are currently made on a specially designed carrier web which imparts the corrugated structure to the films. The elastomer mixture is applied on the carrier web and it is left to cure on the web. The cured elastomer film is then peeled off the web to allow for the deposition of electrodes. The process of releasing the elastomer film from carrier web is not smooth and induces defects and pre-strain in the film. Also, this process is expensive, as it requires miles of carrier web to make the films. Therefore an alternative process to make thin, corrugated elastomer films is required to make the DEAP technology economically competitive with other actuator, generator and sensor technologies.

The hot-embossing process that is usually used in industry for thermoplasts is described in Figure 3 . The polymer in the form of a thin film is heated up to the melting range by conduction. Then the film is compressed to fill the micro-cavities of the mold and then the polymer film is cooled and demolded.[3,4] The force applied on the film into the mold is optimized, regulated and controlled. This serves an inspiration for the following experiments of embossing microstructures on the PDMS films.

* Corresponding author. Tel.: +45252825; fax: +45882258.E-mail address: al@kt.dtu.dk 


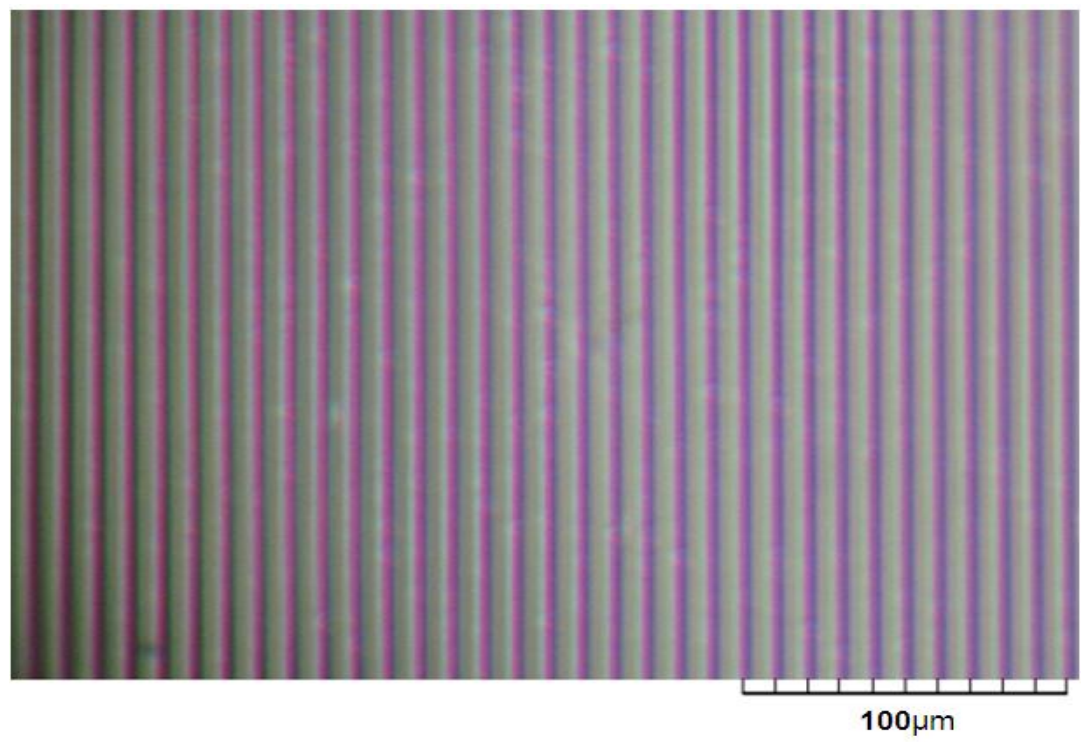

Figure 1. Microscope picture of elastomer film with corrugation lines obtained from the traditional coating process at Danfoss PolyPower A/S. The period of corrugation peaks is $10 \mu \mathrm{m}$ and the depth is $5 \mu \mathrm{m}$, but other aspect ratios are also produced depending on the specific requirements

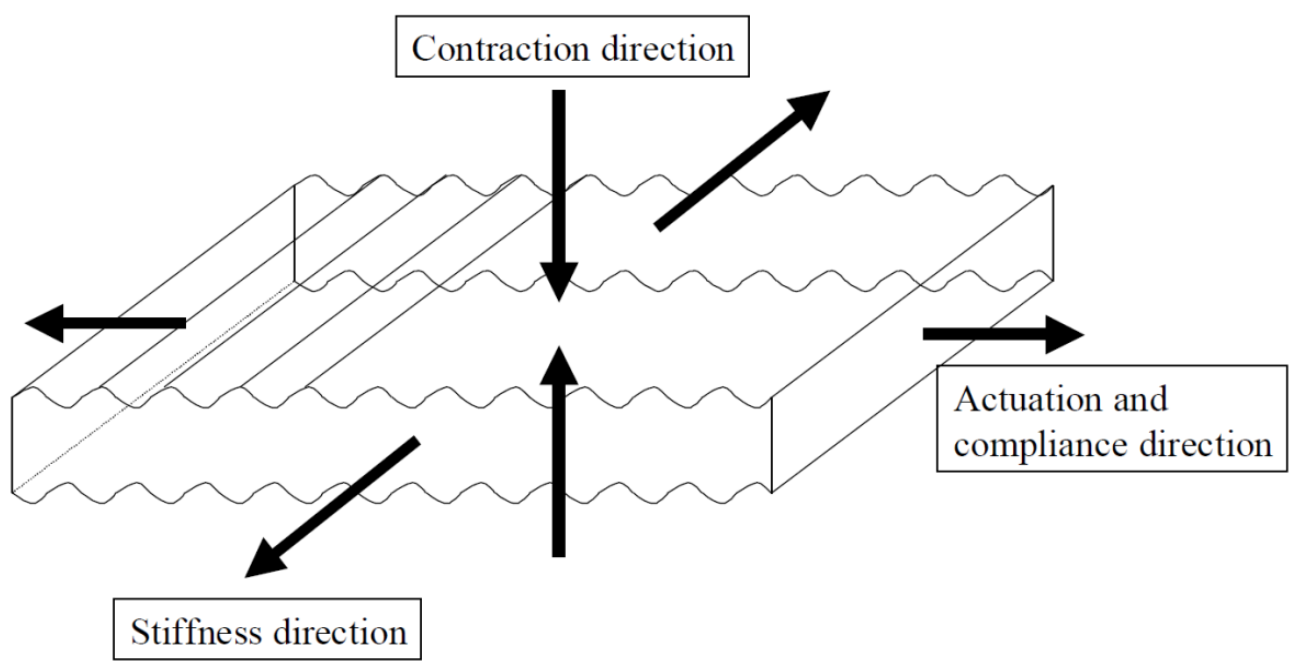

Figure 2. Schematic illustration of a DEAP actuator film with corrugations showing the direction of actuation [2] 


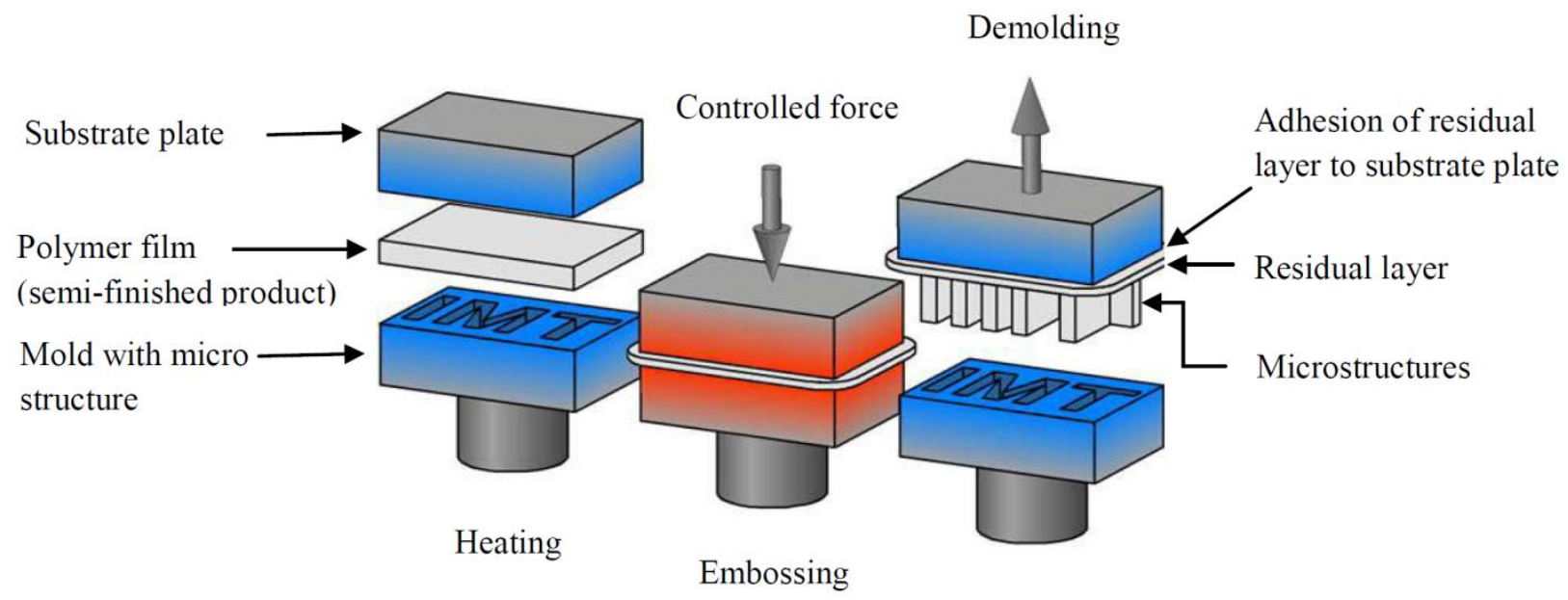

Figure 3. Schematic representation of a typical hot-embossing process for thermoplasts [4]

\section{Experimental}

\subsection{Materials}

The silicone networks used for the hot-embossing process are,

1) Elastosil-RT625 $5^{\circledR}$ - silicone oil (Powersil ${ }^{\circledR}$ fluid TR 50) + inhibitor (Pt 88) which all were obtained from Wacker Chemie AG. Elastosil-RT625 is supplied as premix A and B. Elastosil A contains the crosslinker and elastosil B contains the platinum catalyst. Thus the premixes are inert until mixing. [5]

2) Silastic LC-50-2004 ${ }^{\circledR}$ from Dow Corning + OS-20, an ozone-safe volatile methylsiloxane (VMS) fluid from Dow Corning. It is supplied as a two part system and Silastic A contains the catalyst and Silastic B contains the crosslinker.

\subsection{Instrumentation and specifications}

\subsubsection{Gel point determination}

Rheological measurements to estimate the gel point (GP) of the silicone networks were performed with an AR-2000 (TA instruments, USA) rheometer.

\subsubsection{Carrier web}

The carrier web with micro-scale corrugations was supplied by Danfoss Polypower A/S. The carrier webs are made of temperature stabilized polyethylene terephthalate band $(0.2 \mathrm{~mm})$ coated with methyl acrylate UV resin. The surface of the carrier web has micro-scale corrugations (Figure 4). There are two types of carrier webs used at Danfoss depending on whether the corrugation lines are along the length of the web (down-web) or perpendicular to the length of the web (cross-web). Also there are two types of carrier webs defined by the wave depth and period. One that has a depth of $5 \mu \mathrm{m}$ and a period of $10 \mu \mathrm{m}$ and is capable of stretching to about 35\% strain. Another that has both depth and period of $7 \mu \mathrm{m}$ and this is capable of stretching up to about $80 \%$ strain. $[1,6]$ 

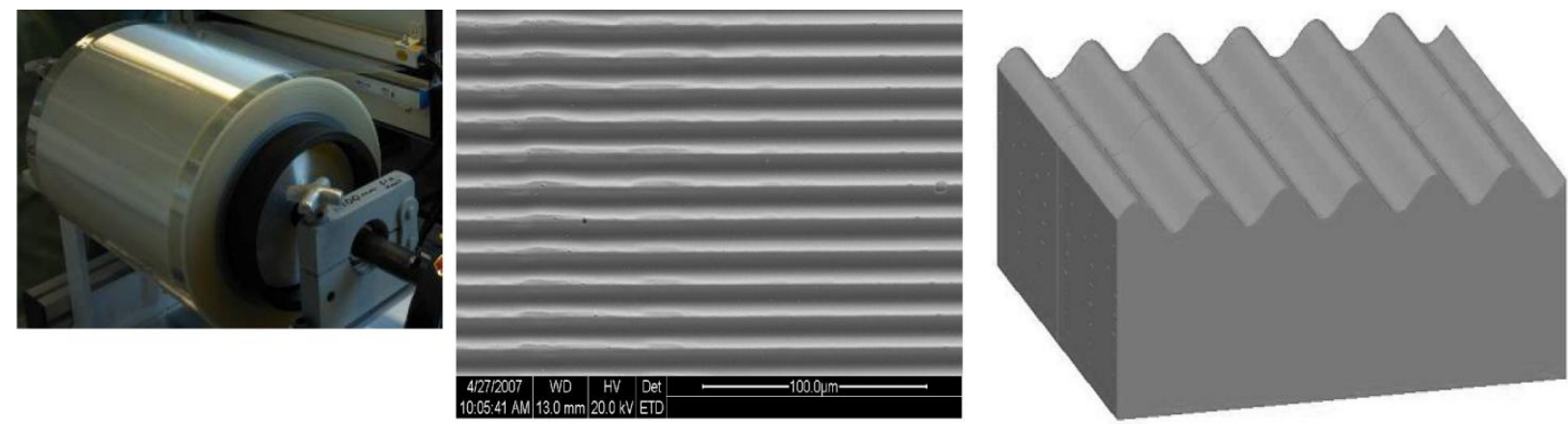

Figure 4. Picture of the carrier web roll (right). Microscope image of corrugation pattern on carrier web (centre). Schematic crosssectional view of carrier web (left) [1]

\subsubsection{Gravure lab coater}

In order to completely control the pressure and speed of the embossing an offset Gravure Lab Coater, 24" wide, Model\#E-BC12POG3 (Euclid Coating Systems Inc., USA) was used for embossing (Figure 5). The diameter of the rolls is 6". With this instrument, the force applied and the speed of the roller can be regulated. The coater is modified to suit the embossing process. Two infra-red lamps are placed one each above the top roller and below the bottom roller to heat them up to a desired temperature. The upper roller of the coater was fixed with a $30 \%$ down carrier web. The period of corrugation peaks are $10 \mu \mathrm{m}$ and the depth is $5 \mu \mathrm{m}$.

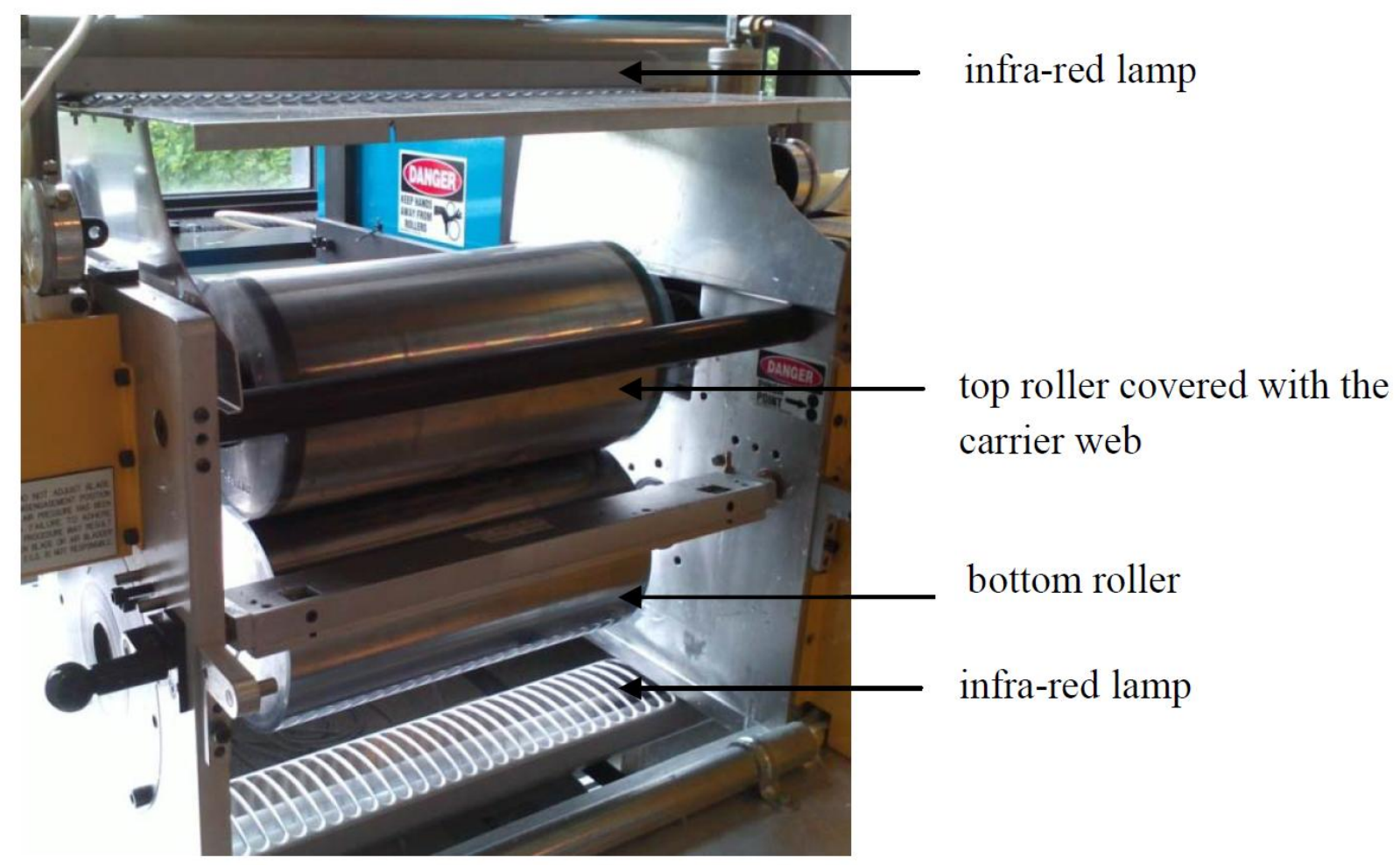

Figure 5. Offset gravure lab coater- used for embossing 


\subsection{Procedure}

There are five steps in the embossing procedure. An overview of the steps involved is shown in Figure 6.

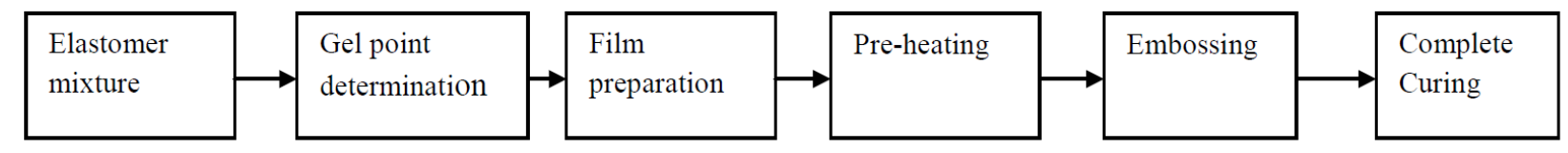

Figure 6. Schematic of the embossing process

\subsubsection{Preparation of the elastomer mixture}

The procedure for making the addition-curable PDMS network is different for each material used. In the following section the details of the different recipes are given.

Elastosil-RT625: Elastosil-RT625 is a room temperature vulcanizing (RTV) silicone supplied as premixes A and B which is recommended to be mixed in ratio 9:1, to form the addition curing mixture. The speed mixer is used to make a uniform mixture (2 minutes @ 2000rpm).

Silastic LC-50-2004: Silastic LC-50-2004, a liquid silicone rubber (LSR), is supplied as premixes A and B and is mixed in the ratio 1:1 using the speed mixer (2 minutes @ 2000rpm). The solvent OS20 is mixed with Silastic in different proportions to reduce the viscosity and thereby ease the processing and initial coating of the films.

\subsubsection{Rheological measurements:}

The gel point (GP) of the silicone network should be investigated before proceeding to embossing process. The time and temperature required to reach GP determines the preheating conditions of the embossing process. The linear viscoelastic measurements during the cross-linking of the stoichiometrically balanced samples 1) Elastosil (A:B=9:1) +15 wt.\% silicone oil +0.8 wt. $\%$ inhibitor and 2) Silastic $(\mathrm{A}: \mathrm{B}=1: 1)+10$ wt. $\%$ of $\mathrm{OS} 20$, at temperatures $110^{\circ} \mathrm{C}, 80^{\circ} \mathrm{C}, 60^{\circ} \mathrm{C}$ and $40^{\circ} \mathrm{C}$ are performed at a controlled strain mode with $2 \%$ strain which is within the linear regime of the material based on an initial strain sweep test and in a frequency range from $100 \mathrm{~Hz}$ to $0.01 \mathrm{~Hz}$.[5,7]

\subsubsection{Film preparation}

Once the elastomer mixtures are ready, films of different thickness are made using 3540 Bird film applicator, (Elcometer, Germany) $(50 \mu \mathrm{m}$ and $100 \mu \mathrm{m})$ and steel frame $(500 \mu \mathrm{m})$ on a PETE (polyethylene terephthalate) substrate.

\subsubsection{Preheating the film}

The films made on the PETE substrate are preheated prior to the embossing till the addition-curing proceeds to the GP. The time and temperature for preheating is fixed based on the GP estimated by rheological experiments. Pre-heating the films in oven rendered films with fully cured surfaces since free surfaces cured faster than the bulk of the film. Such films cannot be embossed. Therefore, preheating in an oven was ruled out. In contrast, a hot plate heats up the film from the bottom, and thereby the film cures from below and the free surface for embossing is still around gel point. The hot plate used is an IKA*C.MAG HS7 (IKA, Germany). It was found that homogenous heat transfer was not possible with a hot plate as the substrate did not have good contact with the hot plate. Later, the films on the PETE substrate were preheated on a hot steel roll with a smooth surface which gave sufficient contact area and hence large and homogeneous heat transfer. Hot steel roll was therefore used for preheating the films. 


\subsubsection{Embossing}

The films which are partly cured by preheating on a steel roller (Figure 7) are immediately embossed using the gravure lab coater. The top roll of the coater is covered with the $30 \%$ down carrier web and hence the top roll acts as the embosser. Both the top and bottom rolls are heated using IR-lamps to a preferred temperature. The temperature of embossing depends on the type of PDMS used. The speed of the rollers and the pressure between the rollers (pressure on the film) is adjusted to give the best results.

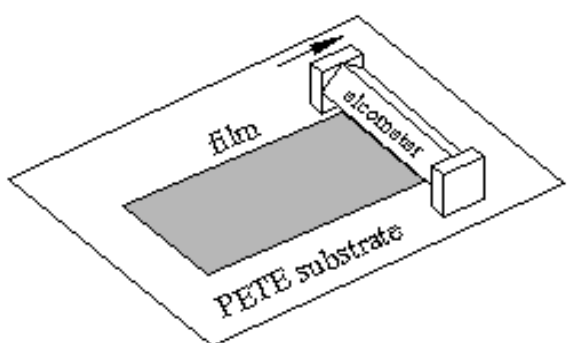

step 1

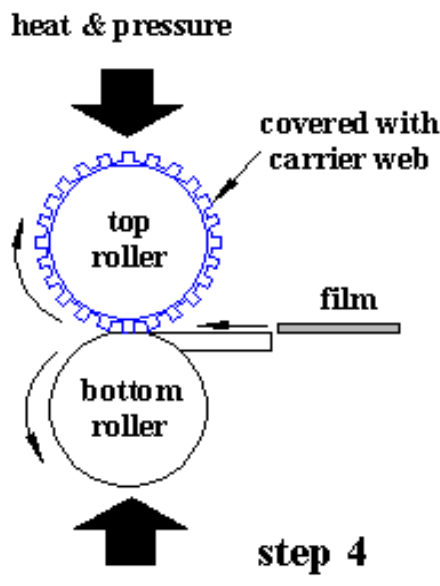

heat \& pressure

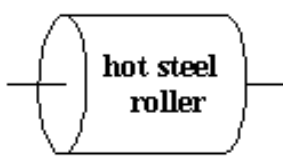

step 2

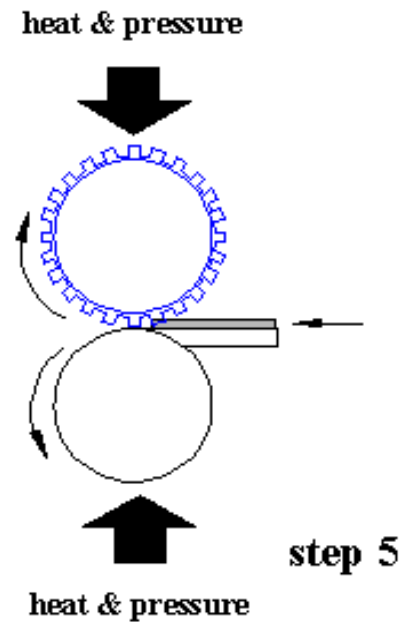

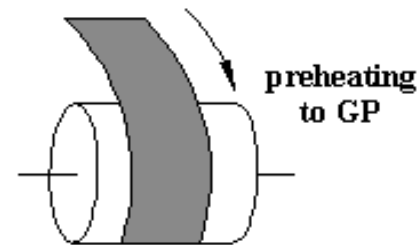

step 3

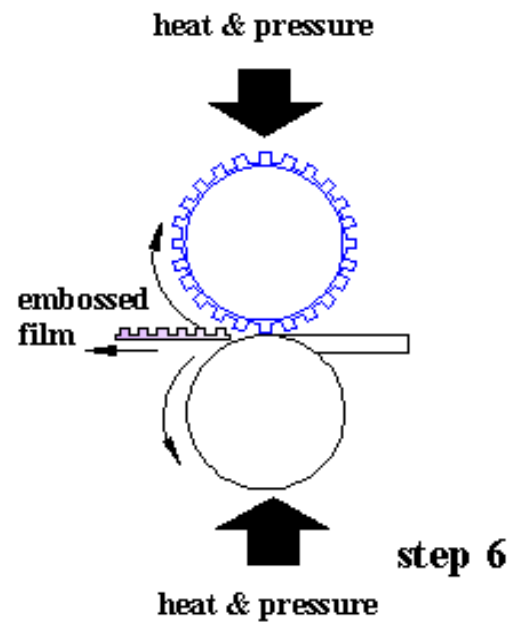

Figure 7. Schematic representation of hot-embossing process with the gravure lab coater

\subsubsection{Complete curing}

The films which are embossed are left to cure completely upon heating in an oven. The temperature and time of curing depends on the material used.

\subsection{Gel point, developing elasticity, and onset of embossing}

After the onset of the hydrosilation reaction, the PDMS network approaches chemical gelation, which is a phenomenon by which a cross-linking polymeric material undergoes a phase transition from liquid to solid state.[8] A cross-linking polymeric system is said to reach its gel point (GP) at a critical extent of the cross-linking reaction at which either the weight average molecular weight diverges to infinity (infinite sample size) or the first macromolecular cluster extends across the entire sample (finite sample size).[8,9] Thus at the GP, a thermosetting polymer system is transformed from a 
viscoelastic liquid to a viscoelastic solid by the introduction of chemical cross-links creating a three dimensional network. There is a dispute as to whether the GP occurs at the cross-point of the storage and loss moduli G' and G' in a LVE (linear viscoelastic) diagram. [9-11] There is one class of polymers only for which the GP coincides with the crossover point. These are the polymers which have a power law relaxation upon reaching the GP $\left(G(t) \sim t^{-n}\right)$, with a specific exponent value $n=\frac{1}{2}$. [11] Stoichiometrically balanced polymer networks or networks with excess crosslinker at temperatures much higher than their glass transition temperature show such behaviour and hence have a GP that coincides with cross-over point of G' and G'. [11]

In the case of the commercial RTV silicone Elastosil RT-625 and the commercial LSR Silastic LC-50-2004 the crossover of G' and G' will be used as the GP, assuming that they are stoichiometrically balanced. Beyond the GP the elasticity increases steadily with increasing cross-linking density. Knowledge of the GP is essential to design the embossing experiments. The higher the temperature, the quicker is the transition from viscoelastic liquid to solid and the less time required to reach GP. The embossing should be started at the GP in hot-embossing because the hydrosilation reaction is much faster at high temperatures and the window for embossing at GP is reduced to a few seconds. At room temperature the reaction rates are much slower and there is a space of 10-15 min after the GP, at which embossing can be done.

The curing profile for Elastosil at $80^{\circ} \mathrm{C}$ is shown in Figure 8. The cross-over happens early in the curing process due to the presence of reinforcing particles in the commercial mixture. Curing profiles for Silastic at $80^{\circ} \mathrm{C}$ and $40^{\circ} \mathrm{C}$ can be seen in Figures 9 and 10, respectively. At $80^{\circ} \mathrm{C}$ Silastic shows similar curing behavior as Elastosil. For the Silastic at $40^{\circ} \mathrm{C}$, there are three cross-points, which are completely reproducible cross-overs. First cross-point is $10 \mathrm{~min}$, second is $69 \mathrm{~min}$ and third is $265 \mathrm{~min}$. The three cross-points are likely to arise due to the competing effect of reaction and solvent evaporation. The Silastic is highly viscous and just a small extent of reaction causes G' to increase. The first two crossovers are due to these competing phenomena and the third cross-over is regarded as the true GP, which is further supported by $\frac{\partial \mathrm{G}^{\prime}}{\mathrm{dt}}$ being strongest at this point. Table 1 shows the GPs of the two materials at $40^{\circ} \mathrm{C}, 60^{\circ} \mathrm{C}, 80^{\circ} \mathrm{C}$ and $110^{\circ} \mathrm{C}$. Figure 11 shows the storage and loss moduli G' and G” of Elastosil and Silastic films as a function of the applied frequency at $23^{\circ} \mathrm{C}$. Silastic film have the highest modulus $(\mathrm{E}=327 \mathrm{kPa})$, which means it is harder than the elastosil $(\mathrm{E}=270 \mathrm{kPa})$.
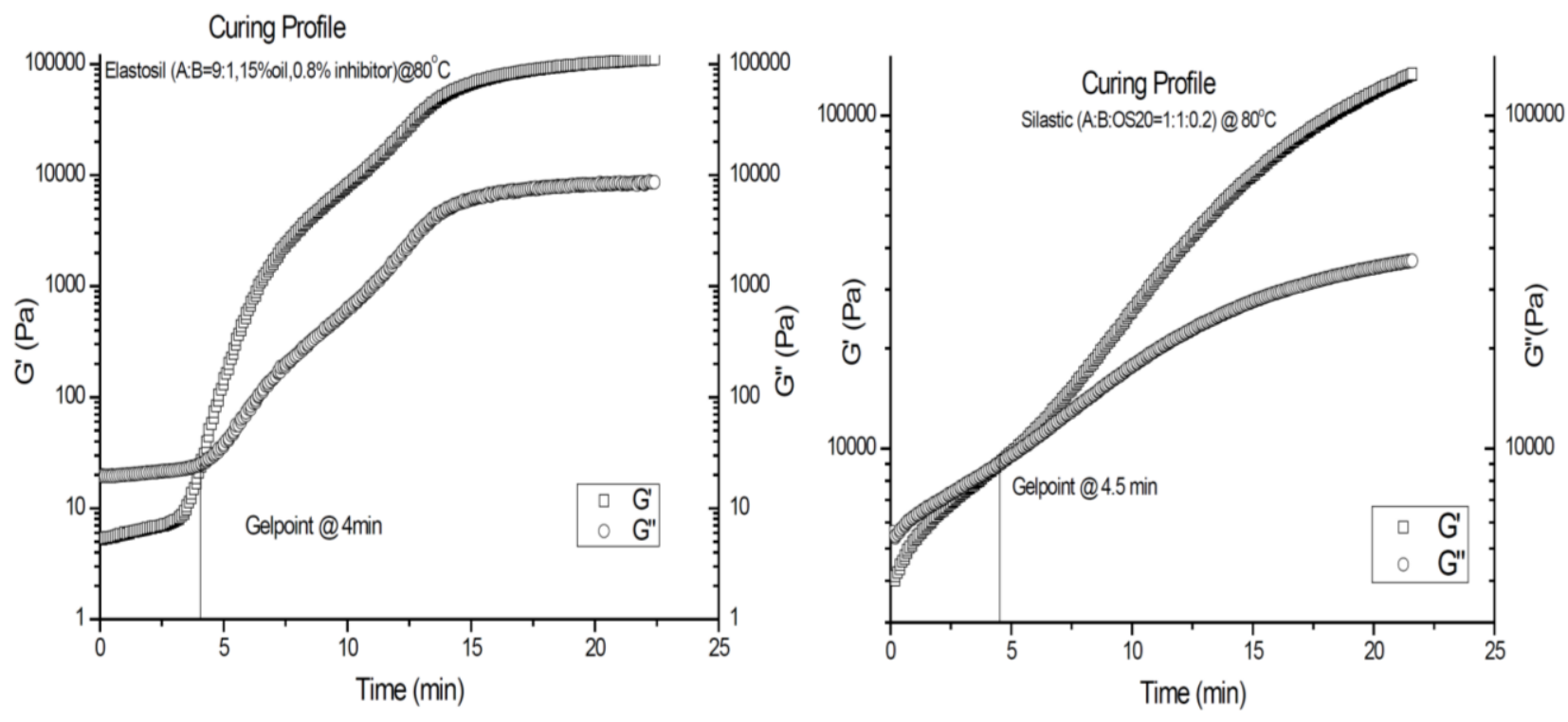

Figure 8. Curing profile of Elastosil at $80^{\circ} \mathrm{C}, \mathrm{GP}$ is at $4.0 \mathrm{~min}$. Figure 9. Curing profile of Silastic at $80^{\circ} \mathrm{C}$, GP is at $4.5 \mathrm{~min}$. 


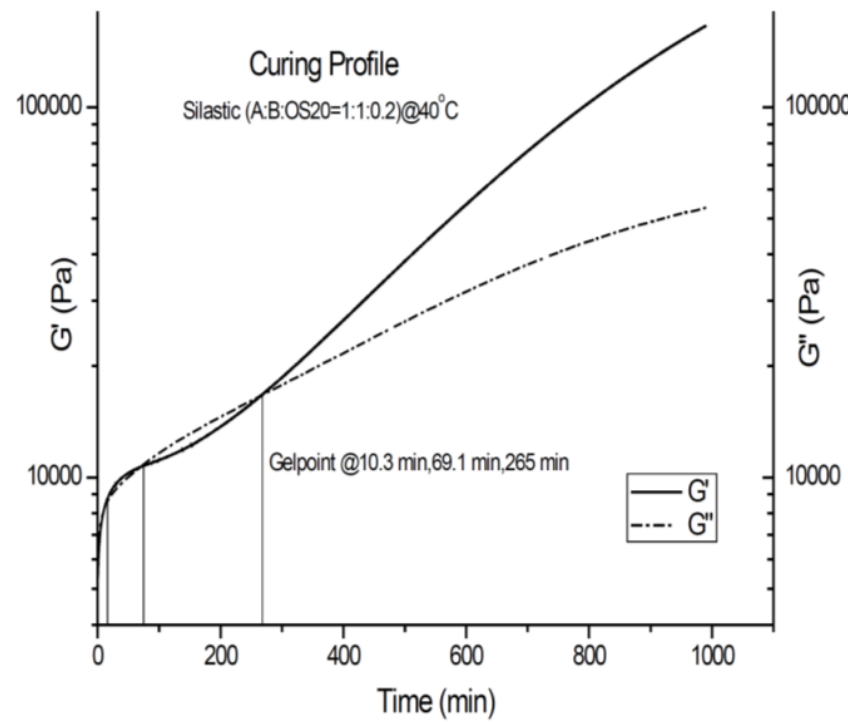

Figure 10. Curing profile of Silastic at $40^{\circ} \mathrm{C}, \mathrm{GP}$ is at $10.3 \mathrm{~min}, 69.1 \mathrm{~min}$ and $265 \mathrm{~min}$.

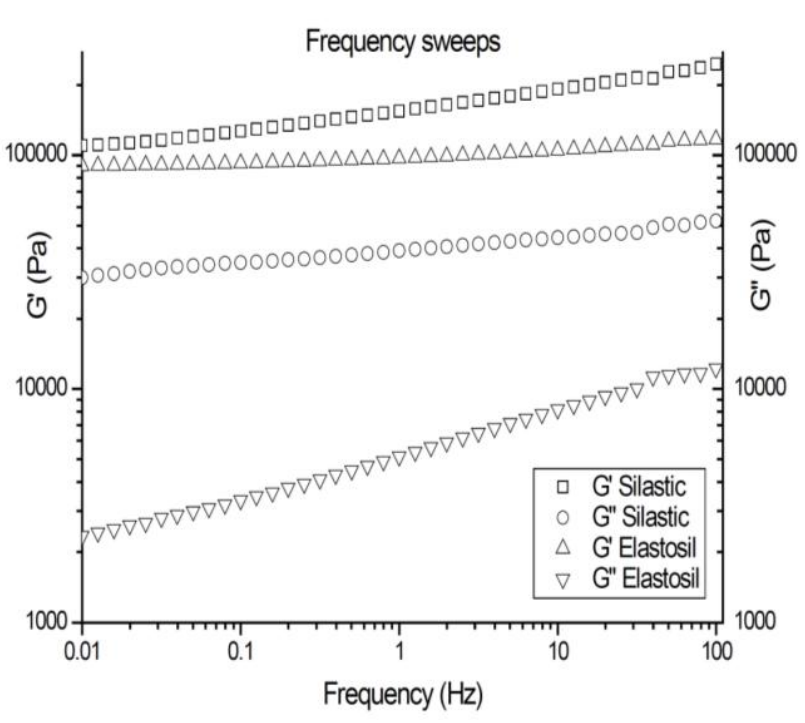

Figure 10. Comparison of the frequency sweeps of Elastosil and Silastic at $23^{\circ} \mathrm{C}$.

Table 1 Gel points of Elastosil and Silastic

\begin{tabular}{ccc}
\hline Temperature & Elastosil & Silastic \\
\hline $40^{\circ} \mathrm{C}$ & $192 \mathrm{~min}$ & $\begin{array}{c}10.3 \mathrm{~min} \text { (first), 69.1 min } \\
\text { (second) and } 265 \mathrm{~min} \text { (third) }\end{array}$ \\
$60^{\circ} \mathrm{C}$ & $30.2 \mathrm{~min}$ & $5.9 \mathrm{~min}$ \\
$80^{\circ} \mathrm{C}$ & $4.0 \mathrm{~min}$ & $4.5 \mathrm{~min}$ \\
$110^{\circ} \mathrm{C}$ & $5 \mathrm{~s}$ & $10 \mathrm{~s}$ \\
\hline
\end{tabular}




\subsection{Requirements for the embossing process}

From the many trials and errors of the embossing process, the most required conditions of embossing process can be established as follows in Figure12.

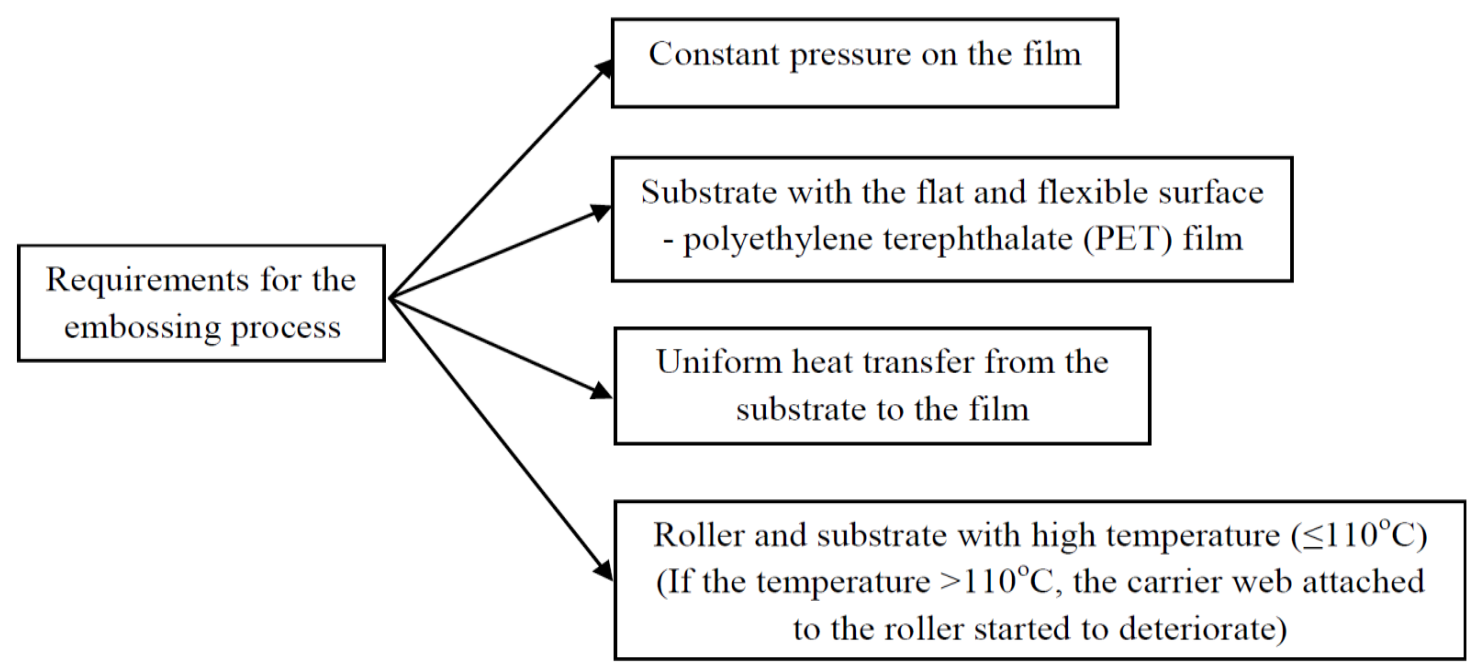

Figure 12. Requirements for the embossing process

\section{Results and discussion}

\subsection{Conditions of embossing process}

At $80^{\circ} \mathrm{C}$ both Elastosil and Silastic have a GP around 4 minutes (refer to table1). Thus, to emboss the mixtures at $80^{\circ} \mathrm{C}$, the film still needs 5 minutes (for Elastosil and Silastic) to develop sufficient elasticity. To further decrease this 'development time' the temperature is increased. When preheated at $110^{\circ} \mathrm{C}$ approximately $5-15$ seconds is sufficient for Elastosil and Silastic to reach GP and embossing can be done on the films.

Euclid coater method: Elastosil film of $100 \mu \mathrm{m}$ thickness embossed with coater at $110^{\circ} \mathrm{C}$ ( 5 seconds to gel point) with a pressure of $25 \mathrm{psi}$ and roller speed of $1.4 \mathrm{rpm}(0.0112 \mathrm{~m} / \mathrm{s})$ gave the best results. Silastic film of $100 \mu \mathrm{m}$ thickness embossed with coater at $110^{\circ} \mathrm{C}(10-12$ seconds to gel point) with a pressure of $20 \mathrm{psi}$ and roller speed of $1.4 \mathrm{rpm}$ gave the best embossing. Table 2 briefs these conditions. Figures 13 and 14 show the microscope pictures of the embossed Elastosil and Silastic films with the best embossing results.

Figure 13 shows the microscope images of embossed Elastosil film of thickness $100 \mu \mathrm{m}$. It was embossed with a $30 \%$ piece of down carrier web (period $\sim 10 \mu \mathrm{m}$ and height $\sim 4 \mu \mathrm{m}$ ). The elastosil film was measured: period $\sim 9.8 \mu \mathrm{m}$ and height $\sim 3.5 \mu \mathrm{m}$, which is $\sim 80 \%$ of carrier web dimensions.

Figure 14 shows the microscope images of embossed Silastic film of thickness $100 \mu \mathrm{m}$. It was embossed with a $30 \%$ piece of down carrier web (period $\sim 10 \mu \mathrm{m}$ and height $\sim 4 \mu \mathrm{m}$ ). The Silastic film measured: period $\sim 10 \mu \mathrm{m}$ and height $\sim$ $4 \mu \mathrm{m}$, which is $\sim 100 \%$ of carrier web dimensions. The results are tabulated in Table 2. 

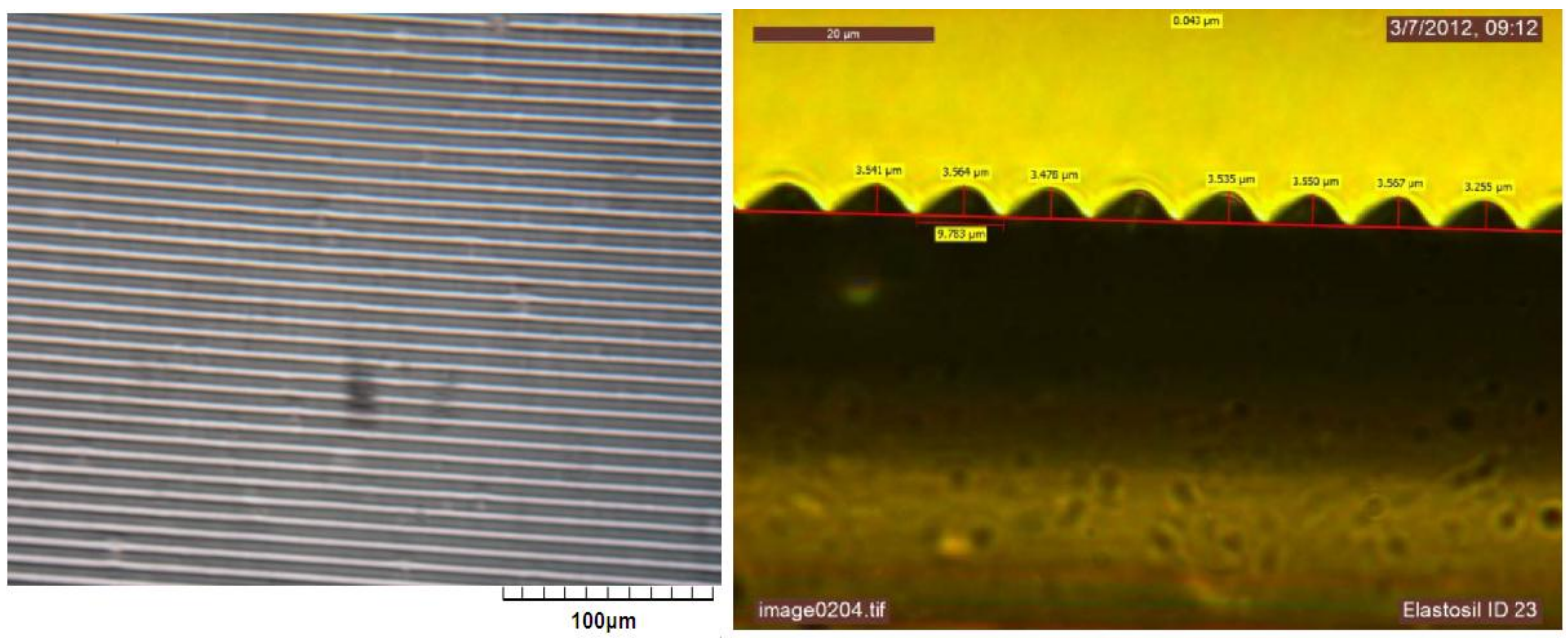

Figure 13. Microscope images of embossed Elastosil film (No.2 in Table 2).

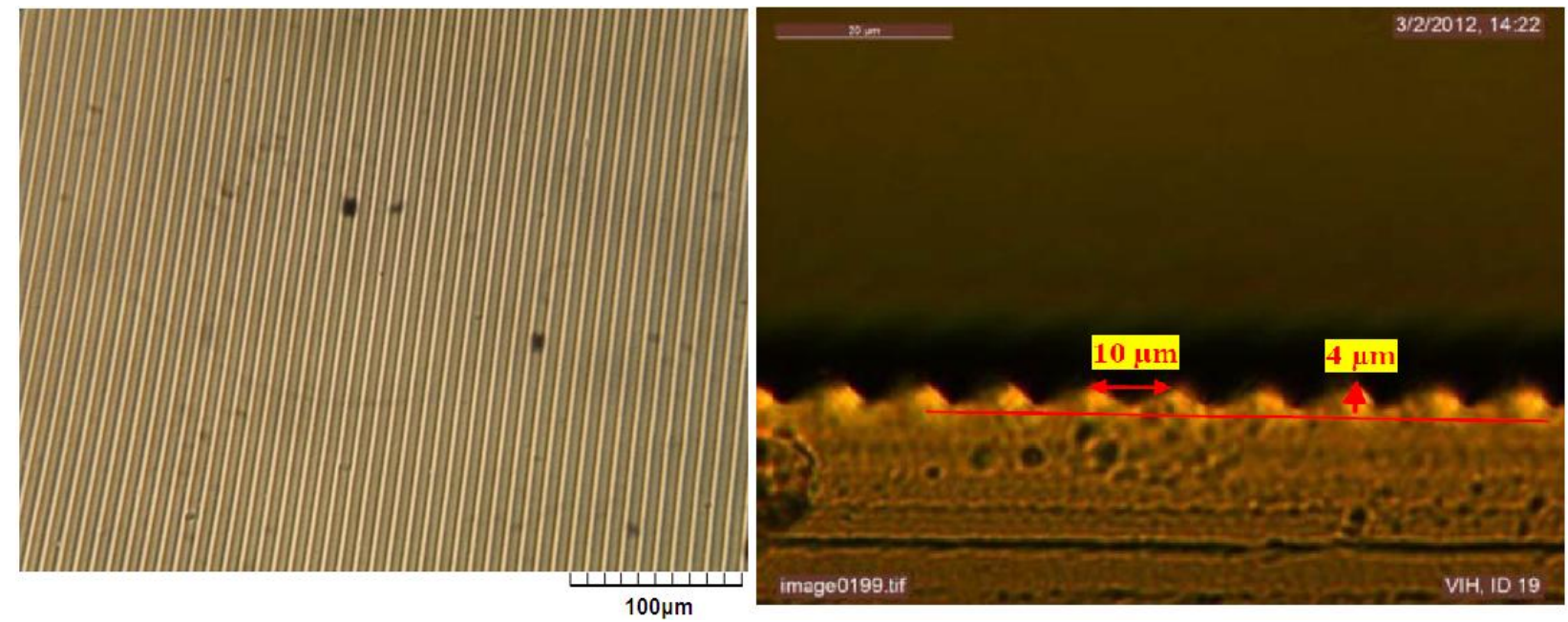

Figure 14. Microscope images of embossed Silastic film (No.5 in Table 2) 
Table 2 Results of embossing process by euclid coater for Elastosil and Silastic films

\begin{tabular}{|c|c|c|c|c|c|c|c|}
\hline No. & Material & $\begin{array}{l}\text { Preheated } \\
\text { on }\end{array}$ & $\begin{array}{l}\text { Preheat } \\
\text { temperature }\left({ }^{\circ} \mathrm{C}\right) \\
\& \text { time of films }\end{array}$ & $\begin{array}{l}\text { Film } \\
(\mu \mathrm{m})\end{array}$ & $\begin{array}{l}\text { Roller speed } \\
\quad(\mathrm{rpm})\end{array}$ & $\begin{array}{l}\text { Roller pressure } \\
\quad \text { (psi) }\end{array}$ & Comments \\
\hline 1 & Elastosil & $\begin{array}{l}\text { Steel } \\
\text { roller }\end{array}$ & 110 (3sec) & 100 & 1.40 & 25 & $\begin{array}{l}\text { Film did not reach GP and it } \\
\text { stuck to the roller while } \\
\text { embossing. }\end{array}$ \\
\hline 2 & Elastosil & $\begin{array}{l}\text { Steel } \\
\text { roller }\end{array}$ & $110(5 \mathrm{sec})$ & 100 & 1.40 & 25 & $\begin{array}{l}\text { Films were at GP and were } \\
\text { embossed fully. }\end{array}$ \\
\hline 3 & Silastic & Hot plate & 150 (10sec) & 100 & 1.40 & 20 & $\begin{array}{l}\text { The methyl-acrylate coating } \\
\text { (the layer carrying the } \\
\text { microstructure) on carrier web } \\
\text { bonded with Silastic, and came } \\
\text { off with the film. }\end{array}$ \\
\hline 4 & Silastic & Hot plate & 110 (10sec) & 100 & 1.40 & 20 & $\begin{array}{l}\text { Film did not reach GP and it } \\
\text { stuck to the roller while } \\
\text { embossing. }\end{array}$ \\
\hline 5 & Silastic & $\begin{array}{l}\text { Steel } \\
\text { roller }\end{array}$ & 110 (10sec) & 100 & 1.40 & 20 & $\begin{array}{l}\text { Films were at GP and were } \\
\text { embossed fully. }\end{array}$ \\
\hline 6 & Silastic & $\begin{array}{l}\text { Steel } \\
\text { roller }\end{array}$ & 110 (10sec) & 100 & 1.40 & 25 & $\begin{array}{l}\text { Film did not reach GP and it } \\
\text { stuck to the roller while } \\
\text { embossing. 'Island formation' } \\
\text { (Figure22.) was seen }\end{array}$ \\
\hline 7 & Silastic & $\begin{array}{l}\text { Steel } \\
\text { roller }\end{array}$ & 110 (10sec) & 100 & 1.85 & 20 & $\begin{array}{l}\text { Corrugation is not deep enough } \\
\text { on the embossed film. }\end{array}$ \\
\hline 8 & Silastic & $\begin{array}{l}\text { Steel } \\
\text { roller }\end{array}$ & 110 (10sec) & 100 & 1.85 & 30 & $\begin{array}{l}\text { Due to high embossing } \\
\text { pressure, film partly stuck on } \\
\text { the web though it was at GP. }\end{array}$ \\
\hline
\end{tabular}

\subsection{Time-window for Hot-embossing}

There are two vital factors for designing the embossing experiments

1) Time to reach GP

2) The time window (around GP) at which the embossing can be performed.

As the temperature of pre-heating and embossing increases $\left(40^{\circ} \mathrm{C}, 60^{\circ} \mathrm{C}\right.$ and $\left.80^{\circ} \mathrm{C}\right)$, the time taken to reach GP and the time window for embossing decreases. At $80^{\circ} \mathrm{C}$ the time available for embossing is still around a few minutes after GP. At $110^{\circ} \mathrm{C}$ the time to reach GP and the time window for embossing is around a few seconds. For industrial processes smaller time windows are preferred, as the production is quicker. In Figure 15 the time window of the embossing process, using the Euclid gravure lab coater for the two materials at $110^{\circ} \mathrm{C}$ is shown. Figure 15 shows a plot of G'/G'final against the time at which preheating is started, followed by embossing. The ratio G'/G' (final) is used instead 
of $G^{\prime}$ in order to make the data comparable (Table 3). The pressure used varies with the material and is indicated in Figure 15 and the speed of the roller is $1.4 \mathrm{rpm}$. In Figure 16, the process window for embossing Elastosil RT-625 is shown.

Table $3 \mathrm{G}^{\prime} / \mathrm{G}^{\prime}$ (final) and GP at $110^{\circ} \mathrm{C}$

\begin{tabular}{rrccc}
\hline Material & GP (s) & G'$^{\prime}(G P) / G^{\prime}($ final) & G'(initial)/G'(final) & G'(final) in Pa \\
Silastic & 10 & 0.047 & 0.0102 & 44570 \\
\hline
\end{tabular}

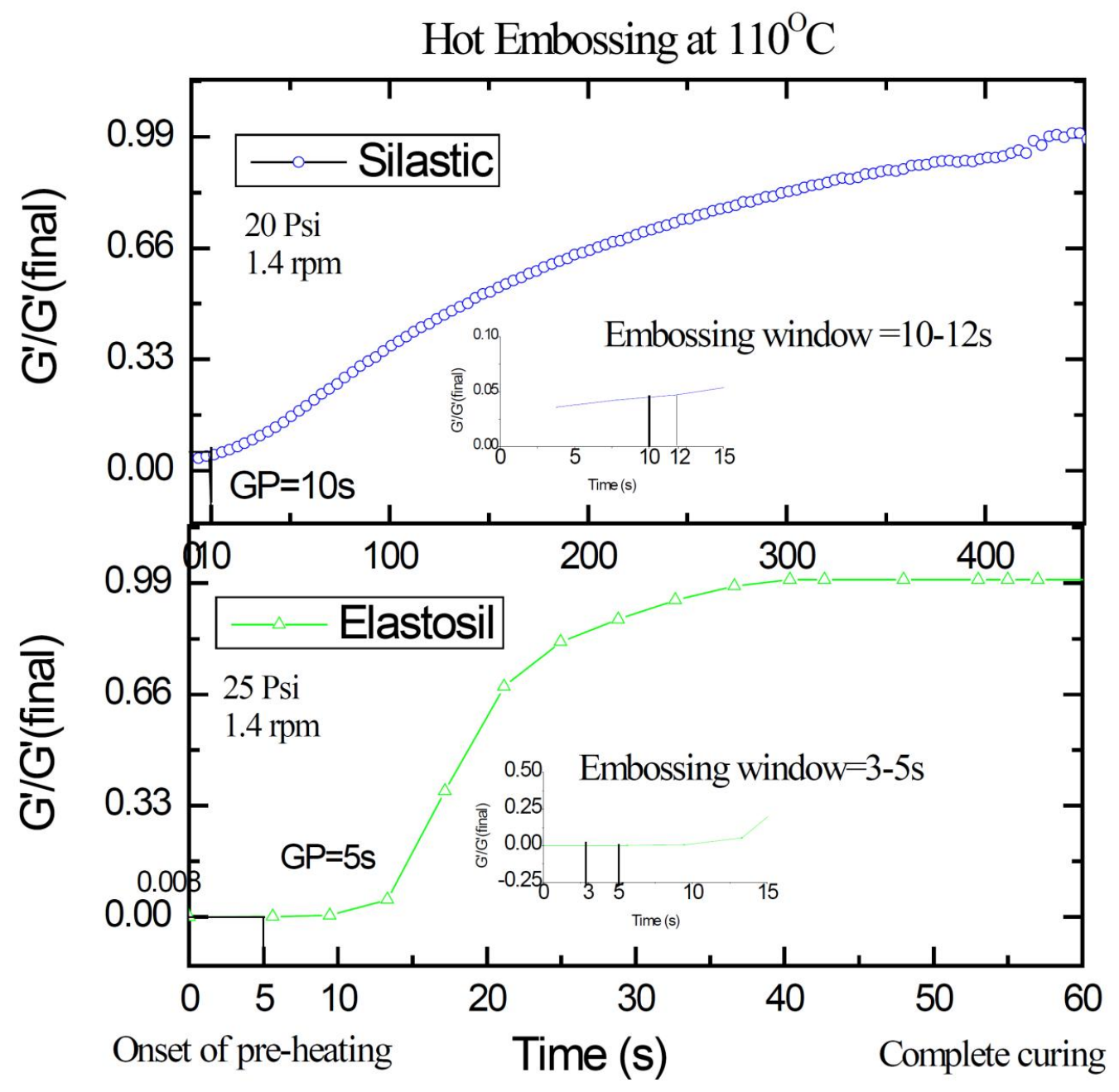

Figure 15. Time- window for embossing at $110^{\circ} \mathrm{C}$ 


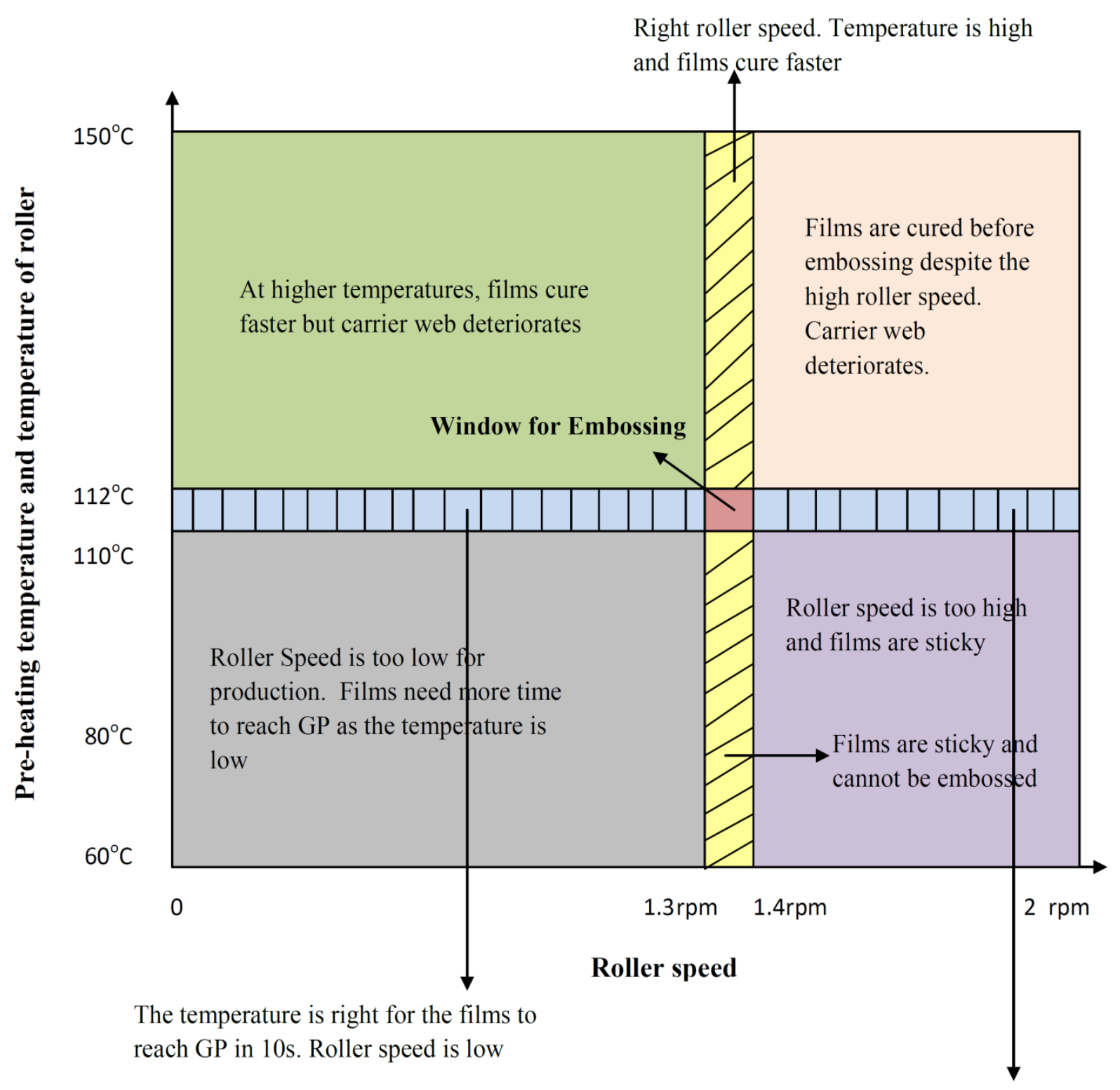

Though the temperature is right, roller speed is high and embossing is not deep enough

Figure 16. Process-window for embossing Elastosil RT-625 at 25 Psi roller pressure, pre-heated for 5 seconds 


\subsection{Problems with embossing}

Pre-heating the polymer film made on the substrate is a very important step in the embossing process. The film needs to be pre-heated uniformly. To ensure uniform heating the film needs to be in good contact with the hot plate. The surface of the hot plate has to be very smooth and should be made of a metal which is a very good conductor and dissipater of heat like steel, copper or aluminum. If the film is not heated uniformly, three cases can happen.

1) Regions of the film which are not in contact with hot plate will not reach the GP,

2) Regions of the film which are in good contact would reach GP or,

3) Some regions of film would have cured completely due to prolonged pre-heating.

The uncured parts of the film stuck to the embossing roller and the fully cured regions of the film did not have any embossing on them as they have hardened fully. The regions which are at GP will be embossed. This results in islandlike structures on the film (as seen in Figure 17).
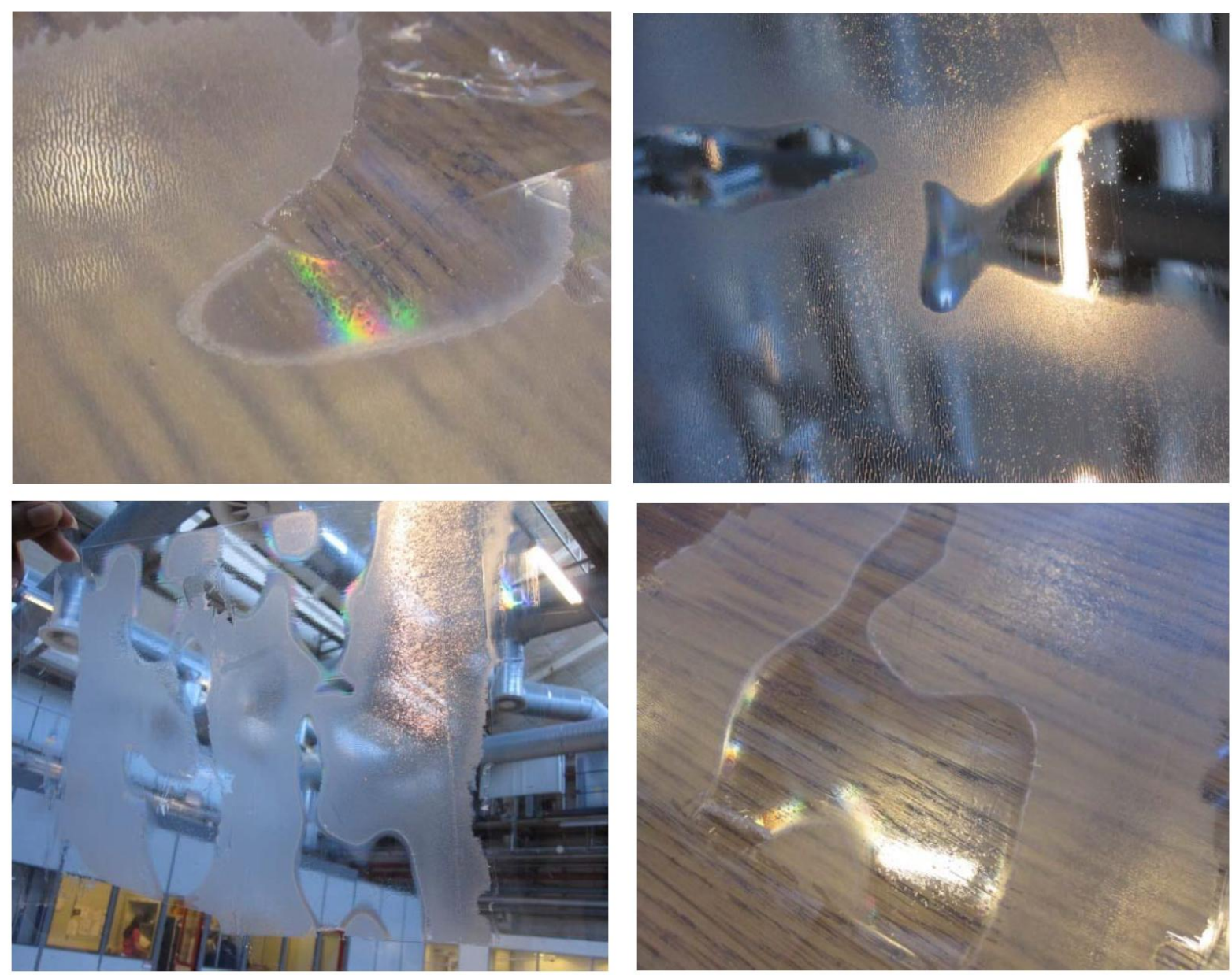

Figure 17. Island formation during embossing process due to non uniform heating. 


\section{Conclusions}

Hot-embossing of silicone elastomer is very different and difficult from embossing thermoplasts. The PDMS elastomer cures and hardens by hydrosilation reaction unlike the thermoplasts which can be melted by heating and hardened by cooling respectively and thus opens up for repeated experiments.

Determining the gel point of the silicone network is the main criteria to design the embossing experiment. Hot embossing is the most cost effective, simple, and a quick method for imprinting microstructures on addition curing PDMS. It can be performed in batch or a continuous process.

Hot embossing of micro-scale corrugation lines on addition curing vinyl terminated polydimethyl siloxane films was successfully performed and the step by step embossing process has been established. The embossing was shown to be possible for two types of silicone elastomers, namely an RTV and an LSR type, with Young's moduli ranging from 270 $\mathrm{kPa}$ to $327 \mathrm{kPa}$, which indicates a great versatility of the process. It is also shown that a given embossing setup could be used for several materials by altering the preheating conditions, pressure and speed of the rollers.

\section{Acknowledgement}

The authors gratefully acknowledge the financial support from the Danish National Advanced Technology Foundation.

\section{References}

[1] Kiil, H. and Benslimane, M.Y., "Scalable industrial manufacturing of DEAP," Proc. SPIE, San Diego, 72870R1-72870R-10 (2009).

[2] Benslimane, M.Y., Kiil, H. and Tryson, M.J., "Dielectric electro-active polymer push actuators: performance and challenges”. Polym. Int. 59(3), 415-21 (2010).

[3] Worgull, M. [Hot Embossing: Theory and Technology of Microreplication] Institute for Microstructure technology, Karlsruhe, Germany. ISBN:978-0-8155-1579-1 (2009).

[4] Kolew, A., Münch, D., Sikora, K. and Worgull, M. "Hot embossing of micro and sub-Microstructured inserts for polymer replication," Microsystem Technologies 17(4), 609-18 (2010).

[5] Bejenariu, A.G., Rasmussen, H.K., Skov, A.L., Hassager, O. and Frankaer, S.M. "Large amplitude oscillatory extension of soft polymeric networks," Rheologica Acta 49(8), 807-14 (2010).

[6] Benslimane, M.Y., Kiil, H. and Tryson, M.J., "Electro-mechanical properties of novel large strain PolyPower film and laminate components for DEAP actuator and sensor applications," Conference on Electroactive Polymer Actuators and Devices (EAPAD), San Diego, 764231: 1-11 (2010).

[7] Larsen, A.L., Hansen, K., Hassager, O., Bach, A., Ndoni, S. and Jørgensen, M. "Elastic Properties of Nonstoichiometric Reacted PDMS Networks," Macromolecules 36(26), 10063-70 (2004).

[8] Venkatraman, S.K. and Winter, H.H. "Finite shear strain behavior of a crosslinking polydimethylsiloxane near its gel point," Rheologica Acta 29(5), 423-32 (1990).

[9] Chambon, F. and Winter, H.H. "Linear Viscoelasticity at the Gel Point of a Crosslinking PDMS with Imbalanced Stoichiometry," Journal of Rheology. 31(8) 683-97 (1987). 
[10] Frankær, S.M.G., Jensen, M.K., Bejenariu, A.G., and Skov, A.L. "Investigation of the properties of fully reacted unstoichiometric polydimethylsiloxane networks and their extracted network fractions," Rheologica Acta 51(6), 559-67 (2012).

[11] Winter, H.H. "Can the Gel Point of a cross-linking polymer be detected by the G'-G" Crossover?" Polymer Engineering and Science 27(22), 1698-702 (1987). 